\title{
Evolution of hair transplantation
}

\author{
Oguz Kayiran ${ }^{1}$, Ercan Cihandide ${ }^{2}$
}

'Sultan Abdulhamid Han Training and Research Hospital, Department of Plastic, Reconstructive and Aesthetic Surgery, Istanbul 34668, Turkey.

${ }^{2}$ Acibadem Atasehir Hospital, Yuniq Plastic Surgery Clinic, Istanbul 34750, Turkey.

Correspondence to: Dr. Oguz Kayiran, Sultan Abdulhamid Han Training and Research Hospital, Department of Plastic, Reconstructive and Aesthetic Surgery, Selimiye Mh., Tibbiye Cd., Istanbul 34668,Turkey. E-mail: droguzk@yahoo.com

How to cite this article: Kayiran O, Cihandide E. Evolution of hair transplantation. Plast Aesthet Res 2018;5:9.

http://dx.doi.org/10.20517/2347-9264.2017.86

Received: 21 Nov 2017 First Decision: 26 Jan 2018 Revised: 1 Mar 2018 Accepted: 2 Mar 2018 Published: 11 Mar 2018

Science Editor: Raúl González-García Copy Editor: Jun-Yao Li Production Editor: Cai-Hong Wang

\begin{abstract}
Aim: Numerous non-surgical methods and surgical options are available for the solution of baldness in the practice. Technology provides mighty weapons in this field. Thus, individualized solutions are best carried out with well-trained and qualified practitioners. Here, a modification of follicular unit extraction, direct hair implantation is introduced with previously licensed unique pens.
\end{abstract}

Methods: Follicular unit extraction and direct hair implantation methods were carried out in 207 hair transplantations between January and December of 2014. The nests for the grafts were created via pieces of hand-cut razor blade in follicular unit extraction. In addition, a new modification of follicular unit extraction, direct hair implantation, is done via pens that are produced for this purpose.

Results: Thirty-eight direct hair implantations were performed in addition with 169 follicular unit extractions. An average number of 2973 grafts were transplanted. Mean operation time was calculated as $385 \mathrm{~min}$.

Conclusion: Hair transplantation is still the best solution for hair loss. In conjunction with the surgery, the addition of non-surgical interventions may give a better result to the patient. On the other hand, the promising results in the field of regenerative medicine with cell-based solutions may alter hair transplantation and change the options solely into this field.

Keywords: Hair transplantation, direct implantation, razor, nest

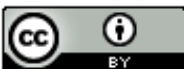

(C) The Author(s) 2018. Open Access This article is licensed under a Creative Commons Attribution 4.0 International License (https://creativecommons.org/licenses/by/4.0/), which permits unrestricted use sharing, adaptation, distribution and reproduction in any medium or format, for any purpose, even commercially, as long as you give appropriate credit to the original author(s) and the source, provide a link to the Creative Commons license, and indicate if changes were made. 


\section{INTRODUCTION}

Hair transplantation has gone through a big revolution with the pioneers in this field ${ }^{[1-5]}$. To achieve a good cosmetic result in hair transplantation, a natural-looking hairline with adequate density shall be established. There are numerous modifications of defined techniques with each one explaining and suggesting verified solutions.

This note describes the available options in hair loss surgery and the concepts of non-surgical approaches, and an experience is shared with a few patients grafted via direct hair implantation (DHI) method. Moreover, to us, this is the only study demonstrating the opening of the nests with sliced razor blade just before the implantation of the hair follicles. Thus, the evolution with the future of hair transplantation is summarized as well. Moreover, this article focuses on the surgical techniques. The medical management of hair loss is out-of-scope.

\section{METHODS}

Between January and December 2014, hair transplantation was carried out in 207 patients. The patients with beard and/or moustache transplantation, multisession transplantations and female patients were excluded. The harvested grafts out of the scalp were also not evaluated.

All the procedures were carried out under local anesthesia. The hair was cut 1-2 mm in length. Micromotor system was used in the harvesting of the hair follicles ${ }^{[6]}$. This system consists of punches attached to the hand-piece of the micromotor system (1500-3000 rpm). Punches were chosen according to the diameter of the follicles ranging between 0.8 and $1.2 \mathrm{~mm}$. Harvesting of the follicles was handled in supine position. With the aid of the sharp punch attached to the motorized system, the follicle was detached from the surrounding tissue (approximately 3-4 $\mathrm{mm}$ in depth=deep dermis layer). Later on, it is released manually with fine-curved microforceps produced for this purpose. Temporooccipital region was used as donor site.

The harvested grafts were aligned in Petri dishes with cooled saline $\left(4^{\circ} \mathrm{C}\right)$. A dressing is made with sterile saline coated gauze to the donor area and the patient was turned to the supine position.

In follicular unit extraction (FUE) technique, razor blade that was cut into pieces was used to open the nests in vertically-oriented fashion that are to be grafted [Figure 1]. With this, we aimed to diminish the incarceration of the implanted follicles. However, in DHI technique, the grafts were loaded to the DHI pens with one charged staff for this purpose [Video 1]. The implantation of the follicles was carried out in accordance with the natural hair angles by the author under loupe magnification [Videos 2 and 3].

After the entire implantation was established, the patient was dressed with antibiotic coated, moisturized gauze to both donor and recipient areas that were removed 3 days later at which the first hair washing would also be carried out. The patients were recommended to have their first hair-cut 15 days later.

\section{RESULTS}

A total number of 615,400 grafts were transplanted in 207 patients. Of these, 38 were DHI (19\%) and 169 had FUE (81\%).

Patients were classified as Norwood III, IV and V in 1 (0.5\%), 30 (14.5\%) and $176(85 \%)$ patients, respectively. The main reasons of hair loss were androgenetic alopecia and cicatricial alopecia in our patients.

An average number of 2973 grafts were transplanted. Mean graft numbers transplanted in FUE and DHI methods were 2982 and 2934, respectively. The mean density was observed around 75 units $/ \mathrm{cm}^{2}$ for DHI technique and 50 units $/ \mathrm{cm}^{2}$ for FUE method. 


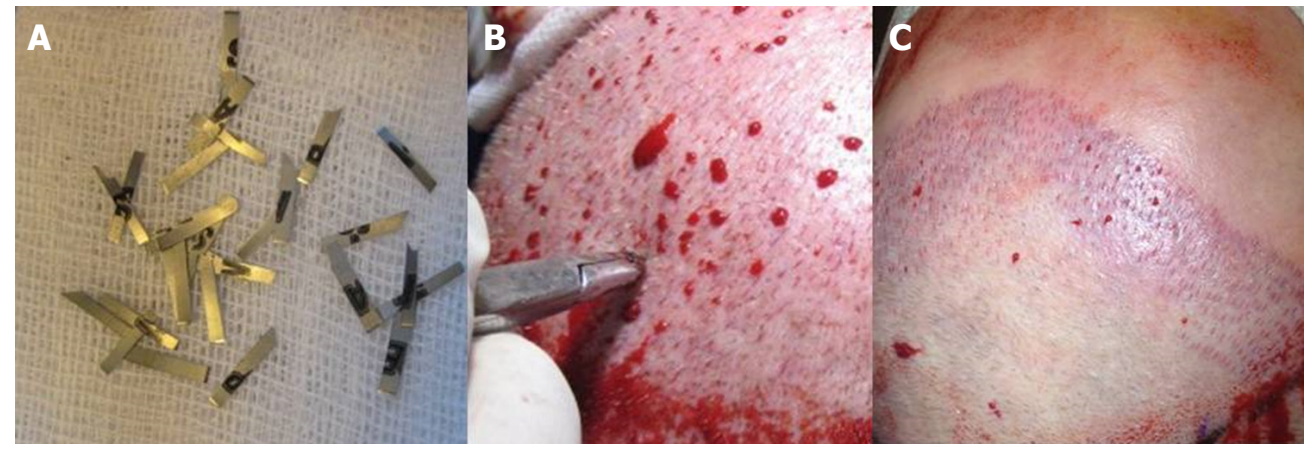

Figure 1. (A) The razor blade is cut into pieces with 1-2 mm sharp edges; (B) perforation is carried out with these pieces held by clamps; (C) these nests are in a vertically-oriented fashion that are ready now for grafting

Table 1. The distribution of the patients

\begin{tabular}{|c|c|c|c|c|c|c|c|c|}
\hline \multirow[t]{2}{*}{ Month of 2014} & \multirow[t]{2}{*}{ Number } & \multirow[t]{2}{*}{ FUE } & \multirow[t]{2}{*}{ DHI } & \multicolumn{3}{|c|}{ Norwood } & \multirow[t]{2}{*}{ Time (min) } & \multirow[t]{2}{*}{ Graft } \\
\hline & & & & III & IV & $\mathbf{v}$ & & \\
\hline January & 11 & 11 & & & 5 & 6 & 359.2 & 2904.5 \\
\hline February & 15 & 15 & & & 1 & 14 & 353.7 & 2733.3 \\
\hline March & 15 & 15 & & 1 & 2 & 12 & 346.3 & 2693.3 \\
\hline April & 15 & 14 & 1 & & 7 & 8 & 354.0 & 2793.3 \\
\hline May & 14 & 13 & 1 & & & 14 & 369.6 & 2842.8 \\
\hline June & 19 & 17 & 2 & & & 19 & 357.1 & 2784.2 \\
\hline July & 21 & 20 & 1 & & & 21 & 349.8 & 2845.2 \\
\hline August & 20 & 12 & 8 & & 3 & 17 & 422.0 & 3145.0 \\
\hline September & 15 & 10 & 5 & & 2 & 13 & 441.3 & 3306.6 \\
\hline October & 19 & 12 & 7 & & 1 & 18 & 392.1 & 3173.7 \\
\hline November & 21 & 16 & 5 & & 3 & 18 & 407.6 & 3157.1 \\
\hline December & 22 & 14 & 8 & & 5 & 17 & 437.7 & 3118.2 \\
\hline Mean & 17.25 & $81 \%$ & $19 \%$ & $0.5 \%$ & $14.5 \%$ & $85 \%$ & 385.0 & 2973.0 \\
\hline Total & 207 & 169 & 38 & 1 & 29 & 177 & & 615,400 \\
\hline
\end{tabular}

FUE: follicular unit extraction; DHI: direct hair implantation

Mean operation time was noted as $385 \mathrm{~min}$ in which mean FUE and DHI times were calculated as 373 and $437 \mathrm{~min}$, respectively. The patients were followed-up between 1 and 5 years. Table 1 describes the distribution of the patients.

None of the patients had infection. Inclusion cyst formation was observed in 4 patients who were treated successfully.

A few results with DHI technique are presented in Figures 2 and 3.

\section{DISCUSSION}

Male type baldness may cause a negative effect on individual's self-esteem. Hair transplantation gives a unique permanent solution for those patients.

Non-surgical therapies for hair loss can be used mainly in early phases. Minoxidil, finasteride, dutasteride, spironolactone or cyproterone acetate can be prescribed in selected patients with temporary actions ${ }^{[7-10]}$. Moreover, low-level light or laser therapy can be utilized in patients with early-phase hair loss where the practitioner may choose home-use and/or in-office systems. It is known that prostaglandin analogues such as prostaglandin F2a and prostaglandin E2 promote hair growth in both mice and human follicles ${ }^{[1]}$. In practice, latanoprost (a prostaglandin F2a analogue) is a solution that provides a significant increase in hair 


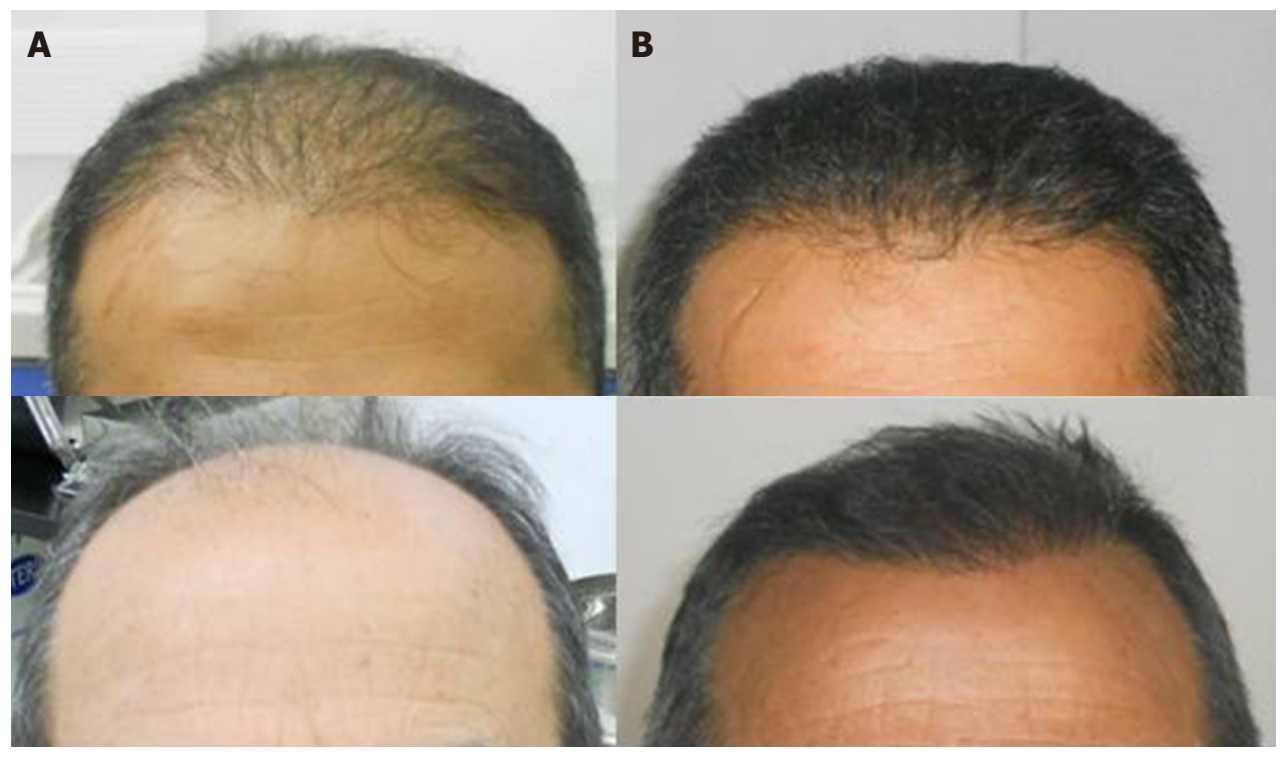

Figure 2. (A, B) A 44-year-old male patient with Norwood type III patient. (A) Preoperative appearance; (B) postoperative 1-year appearance. (C, D) A 51-year-old with Norwood type IV patient. (C) Preoperative appearance; (D) postoperative 1-year appearance

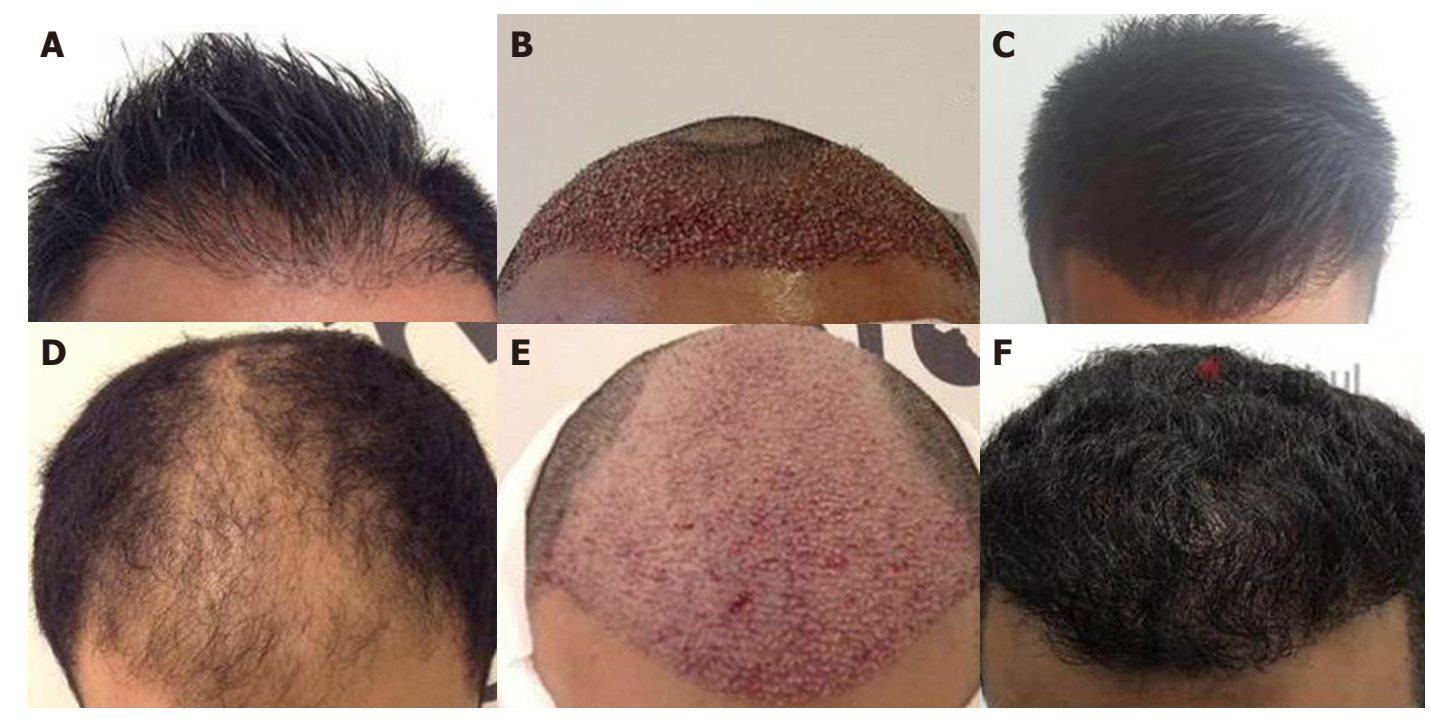

Figure 3. (A-C) A 32-year-old male patient with Norwood type III patient. (A) Preoperative appearance; (B) immediate appearance of the patient after transplantation; (C) postoperative 1-year appearance. (D-F) A 38-year-old with Norwood type $\vee$ patient. (D) Preoperative appearance; (E) immediate appearance of the patient after transplantation; (F) postoperative 1-year appearance

growth $^{[12]}$. Mesotherapy and platelet-rich plasma can be utilized in patients needing additional therapies in the enhancement of hair growth. Mesotherapy consists of superficial injections of pharmaceuticals and vitamin compounds to the follicles. Platelet-rich plasma (PRP) is used in almost every section of the medicine and includes several platelet-derived factors ${ }^{[13]}$. It is proven that PRP injections enhance hair growth in transplanted follicles ${ }^{[14-16]}$. Nevertheless, more studies are needed to evaluate PRP as a hair loss therapy.

Since the concept of "donor dominance" in male pattern hair loss was first published in 1959, it is still not clear why the occipital hair is spared ${ }^{[2]}$. The most accepted reason seems that occipital scalp is not androgen dependent ${ }^{[2]}$. Whatever the reason is, it is the feature that occipital hairs have permanent serves for hair transplantation in both female and male pattern hair loss ${ }^{[2]}$. 
The permanent solution for hair loss can be achieved with hair transplantation. The grafts harvested from the donor area are transplanted to the recipient area in qualified, well-trained hands and at optimum conditions. Nevertheless, graft viability depends on several factors determined by the hair type, delicate technique, physical trauma, vascular factors, biochemical injury, infection, patient disruption, and idiopathic reasons ${ }^{[17]}$.

Hair transplantation is comprised of consecutive steps: planning, preparation, anesthesia, graft harvesting, secure of the harvested grafts, graft transplantation, and dressing. Each step may be individualized in practice. Planning of the patient consists of some blood tests, a thorough history of medical situation, and marking. After shortening of the hair if needed and preparation with antiseptic solutions, anesthesia is carried out. Mostly, local anesthesia is preferred; however, regional anesthesia or local anesthesia with sedation can be chosen. When an entire anesthesia is established, a tumescent solution is injected both to the donor and recipient area. This enables an expansion to harvest the follicles in donor area and graft them easily. The survival of the harvested graft is dependable on temperature, hydration, infection, and trauma ${ }^{[18]}$. The surgeon and staff shall not transect or crush and dehydrate the follicles during the procedure. This meticulous technique will ensure the best outcome. It is also advised to maintain the follicles that are to be transferred in a cold solution in order to reduce the ischemia and reperfusion injury. Some holding solutions exist such as intravenous holding solutions (e.g. normal saline, lactated Ringer), cell culture media (e.g. Dulbecco's Modified Eagle Medium, Williams E) and hypothermic holding solutions (e.g. HypoThermosol, BioLife Solutions, Bothell, WA $)^{[17]}$. Nevertheless, stored grafts are mostly kept cold in ice blocks or cold solutions with the temperature rate between $4{ }^{\circ} \mathrm{C}$ and $10{ }^{\circ} \mathrm{C}$. Harvesting of the follicles can be done via manually or motorized systems. The practitioner can choose sharp or dull tipped punches with a wide variety of diameter and bevel type. Eventually, the follicles are transplanted delicately into the recipient area with appropriate angle to establish similar grow pattern with the normal hair. Nests for the grafts that are to be implanted can be created via a sharp-punch and needles or scalpels in selected sizes ${ }^{[6,19-21]}$. On the front line, we prefer to make the transplantations in a zig-zag fashion to achieve a natural-looking frontal hairline design ${ }^{[19]}$. The number of hair units required for the recipient size can be calculated by the formulas defined for both frontal and vertex regions ${ }^{[22,23]}$. The normal hair density is around $100 \mathrm{units} / \mathrm{cm}^{2[24]}$. In general, the density achieved with hair transplantation is approximately 30-40 units $/ \mathrm{cm}^{2}$. Higher density called as dense packing (up to 60 units $/ \mathrm{cm}^{2}$ ) can be achieved with high viability rates ${ }^{[21,25]}$.

Follicular unit transplantation (FUT) is a widely accepted technique in hair transplantation ${ }^{[26]}$. In this method, the donor area is shaved and an elliptical excision is made for hair follicle harvesting. The dimensions of the ellipse are calculated up to the recipient area that is to be grafted. The donor area is closed meticulously to reduce the scar formation. The collected hair-bearing skin is dissected under magnification and the extra tissues of the hair root as well as the epithelium around are removed as much as possible. The grafts containing clusters of one, two and three follicles are put into Petri dishes containing cooled saline. Later on, the grafts are inserted appropriately to the recipient area.

In contrast to FUT, FUE is a technique with the extraction of follicular units with one or two roots using circular punches. Okuda was the first that used self-made sharp circular punches in various diameters $(1-4 \mathrm{~mm})^{[27]}$. He proposed to use $2-4 \mathrm{~mm}$ punches with regard to $1 \mathrm{~mm}$ because, according to him, the transection rate was interestingly high in $1 \mathrm{~mm}$ harvests. In the market, there are several FUE donor harvesting devices available; of which some are hand-held punches, some are motorized and some are single user-directed robotic system which is also known as Surgically Advanced Follicular Extraction and ARTAS robotic system $\mathrm{s}^{[28-32]}$. Success with FUE depends on being able to predictably dissect excellent-quality grafts with minimum transection rates from the donor region ${ }^{[5,29,33,34]}$.

Ominigraft (Mecicamat S.A., Malakoff, France) has been introduced to optimize mini and micrograft transplantation $^{[29]}$. This device consists of three major parts: hairtome; a hand-held pneumatic graft 
implanter; and a hollow-shafted micromotor handpiece with a punch blade in 0.8-1.25 $\mathrm{mm}$. The transection rates and the operation time are significantly lower with this device.

There are some advantages and disadvantages of FUE over FUT which was very well discussed previously ${ }^{[30]}$. FUE needs longer learning curve and operation time, excellent hand-eye coordination, patience, stamina and hair must be short enough for appropriate harvesting. Moreover, the practitioner may be a candidate for potential repetitive motion disorder in time ${ }^{[30]}$. Besides, the outcomes of FUE may be better and the number of follicles transferred may be higher when compared with FUT. In addition, FUE gives a scarless solution for the patients insisting on not accepting an incision.

Another hair transplantation method, direct hair transplantation, is presented to attenuate the transit time which may reduce the graft survival ${ }^{[8]}$. Here, follicles are implanted as soon as they are harvested. This technique was found a simple and feasible modification of FUE.

An automated FUE technique, Neograft, enables a suction-based follicle harvesting with one or two-step extraction technique. The follicles are collected in a suction canister in which they are transplanted later by using a hand-piece with $0.8,1$ and $1.2 \mathrm{~mm}$ punches that are produced specifically for this purpose. The motor is silent and vibration free; however the steep learning curve and the cost of the machine are the disadvantages ${ }^{[35]}$.

Microrefined microfolliclular hair transplantation is a recently described method in which anterior hairline is constructed with FUE whereas the bald area is transplanted with FUT including strip harvesting (with beveled incisions) and slivering of the strip under magnification. The author proposes the graft transection rate to nearly $0 \%{ }^{[19]}$.

DHI, a modified version of FUE, has similarities with FUE in hair follicle harvesting, whereas the implantation of the follicles is carried out with unique instruments that is licensed by Konstantinos (US 8,801,743 B2) and produced specifically for this purpose. The needle of the pen may vary in size; since there are $0.40-2 \mathrm{~mm}$ oblique-cut needles in the market. After follicle harvesting, each pen is loaded with a micrograft containing 1 to 3 hair follicles and subsequently implanted to the recipient area that was not previously perforated. This technique allows the practitioner graft the recipient area denser and gives less trauma and bloodless field when compared with FUE. Moreover, this procedure lacks additional punching for grafting as noted in other transplantation techniques. On the contrary, the learning curve is high meaning that this surgery needs more qualified personnel per patient. In addition, the procedure is carried out with 3 or 4 personnel, because every stage is assigned to a unique staff which means that the room is more crowded than the other techniques. The pens and so this procedure are relatively expensive when compared to FUT or FUE. Nevertheless, follicle harvesting is significantly cheaper than robotic systems.

Complications after hair transplantation can be placed in the following categories: (1) standard surgical risks; (2) physician planning errors; (3) physician technical errors; (4) patient compliance factors; (5) patient physiology factors; and (6) miscellaneous causes ${ }^{[36]}$. In addition, we may observe some site-specific complications after all including donor and recipient site problems ${ }^{[36]}$. Donor site complications include wide variety of unwanted scar formation, donor-site depletion, wound dehiscence, necrosis, effluvium (shock-loss), hypoesthesia, neuralgia and neuroma and hematoma. Recipient site complications may be comprised of hairline location or shape error, progression error, graft type error, graft placement error, hypopigmentation, hair color mismatch, chronic folliculitis, necrosis, effluvium, ingrown hairs, cysts and low graft yield.

Animal studies reveal creation of human follicles from cultured dermal and epidermal cells in a mouse model $^{[37]}$. A revolutionary breakthrough in this field is the discovery of induced pluripotent stem cells enabling 
to reprogram differentiated fibroblasts into an embryonic stem cell state ${ }^{[38,39]}$. A recent study exhibits the creation of a bioengineered hair follicle germ using embryonic skin-derived epithelium and mesenchymal donor cells where the transplanted germ integrate to the host epithelium producing a complete functional hair ${ }^{[40]}$. A recent study revealed the generation of folliculogenic human epithelial stem cells from induced pluripotent stem cells ${ }^{[4]}$. The regenerated hair follicles possed a KRT15+ stem cell population and produced hair shafts expressing hair specific keratins. These results suggest an approach for generating large numbers of human epithelial stem cells for tissue engineering and new treatments for hair loss, wound healing and other degenerative skin disorders.

Forthcoming studies will ensure better results. As the technology contributes to the medicine, it is possible that the whole process will be carried out entirely with robotic and automated systems. Indeed, the future may give the solutions by solely cell-based applications enabling hair growth without a surgery. Up-to-date, I believe that the combination of the surgical methods with the help of additional options may give the best option for the patients to re-gain their natural-looking hair with adequate density.

\section{DECLARATIONS}

\section{Authors' contributions}

Concept, design, resource, data collection and processing, and manuscript writing: Kayiran O, Cihandide E Supervision, literature search, analysis and interpretation: Kayiran O

\section{Data source and availability}

Data in this study were derived from searches of the PubMed database.

\section{Financial support and sponsorship}

None.

\section{Conflicts of interest}

There are no conflicts of interest.

\section{Patient consent}

Consents from all of the patients were established prior to submission.

\section{Ethics approval}

Local Committee of Ethics approved this study with SAH-17-214.

\section{Copyright}

(c) The Author(s) 2018.

\section{REFERENCES}

1. Barrera A. Advances in aesthetic hair restoration. Aesthet Surg J 2003;23:259-64.

2. Orentreich N. Autografts in alopecia and other selected dermatological conditions. Ann N Y Acad Sci 1959;83:463-79.

3. Shiell RC. A review of modern surgical hair restoration techniques. J Cutan Aesthet Surg 2008;1:12-6.

4. Rose PT. The latest innovations in hair transplantation. Facial Plast Surg 2011;27:366-77.

5. Uebel CO. Micrografts and minigrafts: a new approach for baldness surgery. Ann Plast Surg 1991;27:476-87.

6. Ors S, Ozkose M, Ors S. Follicular unit extraction hair transplantation with micromotor: eight years experience. Aesthetic Plast Surg 2015;39:589-96.

7. Nusbaum AG, Rose PT, Nusbaum BP. Nonsurgical therapy for hair loss. Facial Plast Surg Clin North Am 2013;21:335-42.

8. Sethi P, Bansal A. Direct hair transplantation: a modified follicular unit extraction technique. J Cutan Aesthet Surg 2013;6:100-5.

9. Bernstein RM, Rassman WR. Follicular unit transplantation. In: Haber RS, Stough DB, editors. Hair Transplantation. Philadelphia: Elsevier Saunders; 2006. p. 91-8. 
10. Bouhanna P. Androgenetic alopecia: combining medical and surgical treatments. Dermatol Surg 2002;28:136-42.

11. Garza LA, Liu Y, Yang Z, Alagesan B, Lawson JA, Norberg SM, Loy DE, Zhao T, Blatt HB, Stanton DC, Carrasco L, Ahluwalia G, Fischer SM, FitzGerald GA, Cotsarelis G. Prostaglandin D2 inhibits hair growth and is elevated in bald scalp of men with androgenetic alopecia. Sci Transl Med 2012;4:126-34.

12. Blume-Peytavi U, Lönnfors S, Hillmann K, Garcia Bartels N. A randomized double-blind placebo-controlled pilot study to assess the efficacy of a 24 -week topical treatment by latanoprost $0.1 \%$ on hair growth and pigmentation in healthy volunteers with androgenetic alopecia. J Am Acad Dermatol 2012;66:794-800.

13. Li ZJ, Choi HI, Choi DK, Sohn KC, Im M, Seo YJ, Lee YH, Lee JH, Lee Y. Autologous plateletrich plasma: a potential therapeutic tool for promoting hair growth. Dermatol Surg 2012;38:1040-6.

14. Rinaldi F, Sorbellini E, Bezzola P. Improving the revascularization of transplanted hair follicles through up-regulation of angiogenic growth factors. Hair Transplant Forum Int 2005;17:117-26.

15. Greco J, Brandt R. Preliminary experience and extended applications for the use of autologous platelet-rich plasma in hair transplantation surgery. Hair Transplant Forum Int 2007;17:131-2.

16. Uebel CO, da Silva JB, Cantarelli D, Martins P. The role of platelet plasma growth factors in male pattern baldness surgery. Plast Reconstr Surg 2006;118:1458-66.

17. Cooley JE. Optimal graft growth. Facial Plast Surg Clin North Am 2013;21:449-55.

18. Parsley WM, Perez-Meza D. Review of factors affecting the growth and survival of follicular grafts. J Cutan Aesthet Surg 2010;3:6975.

19. Gupta A. Microrefined microfollicular hair transplant: a new modification in hair transplant. Ann Plast Surg 2014;73:257-65.

20. Stough DB 4th, Nelson BR, Stough DB 3rd.Incisional slit grafting. J Dermatol Surg Oncol 1991;17:53-60.

21. Nakatsui T, Wong J, Groot D. Survival of densely packed follicular unit grafts using the lateral slit technique. Dermatol Surg 2008;34:1016-22.

22. Bernstein RM. Measurements in hair restoration. Hair Transplant Forum Int 1998;8:27.

23. Chang SC. Estimation of number of grafts and donor area. Hair Transplant Forum Int 2001;11:101-3.

24. Bernstein RM, Rassman WR. The logic of follicular unit transplantation. Dermatol Clin 1999;17:277-95.

25. Unger WP. Density issue in hair transplantation. Dermatol Surg 1998;24:297.

26. Bernstein RM, Rassman WR, Szaniawski W, Halperin A. Follicular transplantation. Int J Aesth Rest Surg 1995;3:119-32.

27. Okuda S. The study of clinical experiments of hair transplantation. Japan J Dermatol Urol 1939;46:135-8.

28. Onda M, Igawa HH, Inoue K, Tanino R. Novel technique of follicular unit extraction hair transplantation with a powered punching device. Dermatol Surg 2008;34:1683-8.

29. Avram MR, Watkins SA. Robotic follicular unit extraction in hair transplantation. Dermatol Surg 2014;40:1319-27.

30. Williams KL Jr. Current practices and controversies in cosmetic hair restoration. Dermatol Surg 2013;39:797-801.

31. Harris JA. New methodology and instrumentation for follicular unit extraction: lower follicle transection rates and expanded patient candidacy. Dermatol Surg 2006;32:56-61.

32. Rashid RM. Follicular unit extraction with the Artas robotic hair transplant system system: an evaluation of FUE yield. Dermatol Online $J$ 2014;20:22341.

33. Gökrem S, Baser NT, Aslan G. Follicular unit extraction in hair transplantation: personal experience. Ann Plast Surg 2008;60:127-33.

34. Cole JP. An analysis of follicular punches, mechanics, and dynamics in follicular unit extraction. Facial Plast Surg Clin North Am 2013;21:437-47.

35. NeoGraft Hair Transplant Machine for FUE (2005). Retrieved July 27, 2012. Available from: https://www.bernsteinmedical.com/hairtransplant/fue/devices/neograft [Last accessed on 5 Mar 2018]

36. Konior RJ. Complications in hair-restoration surgery. Facial Plast Surg Clin North Am 2013;21:505-20.

37. Li S, Thangaparzham RL, Wang JA, Rajesh S, Kao TC, Sperling L, Moss J, Darling TN. Human TSC2-null fibroblast-like cells induce hair follicle neogenesis and hamartoma morphogenesis. Nat Commun 2011;2:235.

38. Marshall BT, Ingraham CA, Wu X, Washenik K. Future horizons in hair restoration. Facial Plast Surg Clin North Am 2013;21:521-8.

39. Takahashi K, Yamanaka S. Induction of pluripotent stem cells from mouse embryonic and adult fibroblast cultures by defined factors. Cell 2006;126:663-76.

40. Toyoshima KE, Asakawa K, Ishibashi N, Toki H, Ogawa M, Hasegawa T, Irié T, Tachikawa T, Sato A, Takeda A, Tsuji T. Fully functional hair follicle regeneration through the rearrangementof stem cells and their niches. Nat Commun 2012;3:784.

41. Yang R, Zheng Y, Burrows M, Liu S, Wei Z, Nace A, Guo W, Kumar S, Cotsarelis G, Xu X. Generation of folliculogenic human epithelial stem cells from induced pluripotent stem cells. Nat Commun 2014;5:3071. 